\title{
Intercultural Education - Motivating and Growing Factor of the Didactic Act among Teachers and Pupils
}

\author{
Irina Antoaneta Tănăsescu \\ dtanasescu2212@yahoo.fr \\ Valahia University of Targoviste, Romania \\ Monica Raducanu \\ raducan.monica@gmail.com \\ Dunărea de Jos University of Galati, Romania
}

\begin{abstract}
The quality of the educational act represents an imperative of present times. The integration of learning the contents of the disciplines with innovative elements, such as communicational skills in foreign languages and knowledge of different cultures, creates that energising condition which provides an impetus toward self-perfection and actually constitutes motivation. Motivated pupils mean performing pupils who create, in their turn, motivation and satisfaction among teachers. The motivation-satisfaction relation is a biunique one within the framework of the teacher-pupil partnership. In this paper we have researched the sources and the determinants of this binomial which ensures the quality and the progress of the education in a globalised intercultural environment that presents variables with significantly positive and also negative influences which combine with the individual factors of the participants to the didactic act.
\end{abstract}

Key words: motivation, satisfaction, interculturalism, quality of education

\section{Introduction}

This paper seeks to study some new resources which create motivation and satisfaction in the educational act, in the context newly created by the streamlining of national borders and the free movement of people in their attempt to fulfil their professional and spiritual aspirations. The individual nowadays is searching a wider access to the European and worldwide social life. In this respect, managing the cultural and linguistic diversity is vital. This desideratum entails changes in the educational process which should ensure both knowledge of a distinct professional field and a cumulus of communicational and socio-cultural skills which should enable the dialogue, the cooperation in multicultural teams.

Consequently, the content of any discipline should also encompass elements composing other cultural systems than its own.

From this perspective, the acquisition of some information will be much more valued by pupils who will develop new approaching ideas themselves and therefore consolidate the free exchange of opinion between the teachers and their disciples.

\section{Aspects on the relation between learning motivation and social success}

The issue of the teachers' and pupils' motivation in the learning process has been a concern to the decision-making factors in the Romanian education for some time. The Institute of Education Sciences implemented between 2015 and 2016 a comprehensive research project in this domain, of which results were exploited in strategic decisions made by the Ministry of National Education in the following years.

A component of the final report on the research was the presentation of the results of a study carried out as early as 2004, on a national sample representative for the senior students in secondary schools and in schools of arts and crafts. 
"The conclusion of the research is that school is deficient when it comes to providing models; it shows no interest in pupils' models, has nothing to do with real life, fails to provide useful/concrete/applicable information, is not centred on pupils, their needs and interests"12

In 2014, the Institute of Education Sciences conducted a qualitative research in 23 schools in seven counties and Bucharest, with the focus on the pupils' culture and the way in which the school exploits the specific elements of this culture in the educational process.

The results of the research highlighted characteristics of both teachers and pupils' behaviour and profiles which constitute arguments for reconsideration and re-conceptualisation of the supply and demand relation in the educational performance. ${ }^{13}$

"The children of our times are independent, original, creative, curious, sociable, communicative. They have a strong desire to come forward; they feel the need for privacy. They are sensitive, well-informed, skilled in using new technologies, they have a very alert lifestyle; nevertheless, they are focused on the image, sometimes being superficial and lazy.

The teachers denounce the degradation of their social status, the decrease of their authority and prestige in relation to their pupils; they feel the social pressure and condemn the parents' lack of responsibility and the excessive accountability of the school with regard to the children's education".

In its essence, motivation is the individual's behaviour toward reaching a certain goal. We are reiterating in short the main motivational theories existing in the literature:

Attribution theory - elaborated by Bernard Weiner ${ }^{14}$ asserts that the individuals are committed to the implicit analysis of the reasons leading to some results: "If Ionel failed in the maths test and he believes that this is due to the fact that he has poor maths skills (lack of ability), he feels he cannot change this situation and has no control over it. This belief makes him feel embarrassed, and he will avoid to properly prepare for a new test. If he considers that the failure is due to his lack of effort (insufficient effort), he will feel uncomfortable as he is aware that he could have done much better in the test if he had put more effort into it, fact which will likely urge him to prepare for the new test ahead of time and more efficiently."

Goal orientation theory (John Nicholls, Conel Dweck, Martin Covington) ${ }^{15}$ is focused on the individuals' goals in successful situations. Nicholls and Dweck consider that the first goal is that the individual should demonstrate a high ability or, at least, should not have negative assessments of such ability. They claim that pupils and adults have their own theory on intelligence. Some perceive intelligence as a fixed feature. The failure is difficult to avoid and they underestimate their previous successes. Others see intelligence as a dynamic characteristic which may be developed by knowledge and skills. Both goal orientations may lead either to confrontation behaviour or an avoidance behaviour, the latter creating a tense relation between motivation and learning.

In addition to lack of motivation, Martin Covington identifies another cause of school failure. He asserts that the pupils are consciously and willingly passive and self-protective. They set high goals which they fail to achieve and turn such failure into a proof of nonconformism and a manifestation of their individuality.

Expectancy-value theory (J.Eccles, A, Wigfield)

In this model, a person's perceptions on one's ability and the estimation of the task difficulty level are essential (Fig.1.).

\footnotetext{
12 Popenici, SSt. (coord.)- "Learning Motivation and Social Success", I.S.E. Publishing House, Bucharest, 2005, p.34

${ }_{13}$ Cuciureanu, M. (coord.) "Pupils' Culture and Learning", I.S.E. Publishing House, București, 2014, p.37

${ }^{14}$ Cuciureanu, M (coord.) "Pupils' Motivation and Learning", I.S.E. Publishing House, Bucharest, 2015, p.7

${ }^{15}$ Idem p.8-10
} 


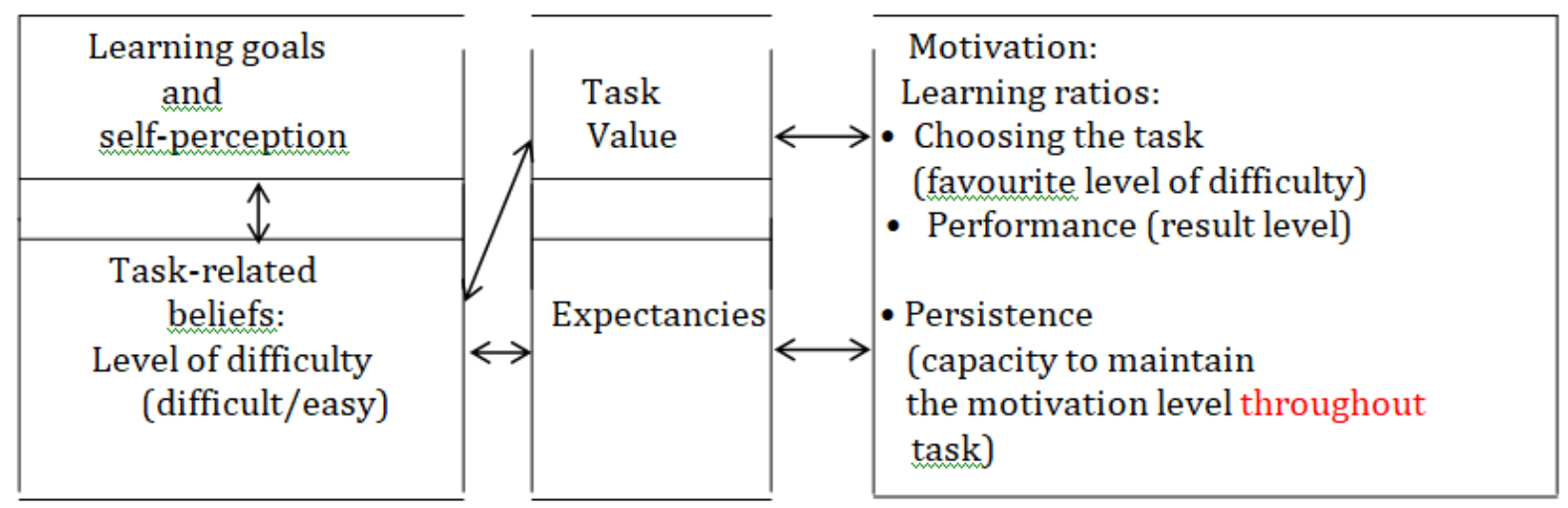

Fig.1. Schematic presentation of Eccles and Wigfield's model Source: Cuciureanu, $M$ (coord.) 'Pupils' Motivation and Learning", I.S.E. Publishing House, Bucbarest, 2015, p.14

These connexions proposed by the model demonstrate that the motivational process is the result of the corroboration of the cultural concept with the socialising practices determined by parents/tutors and the educational practices.

Self-efficacy is based on the individual's self-esteem and belief that he/she is able to reach the goals set. A pupil who works hard and gets poor results will blame the teacher's grading system. It is the role of the teacher to follow the pupil's evolution and to help him/her to overcome the loser's attitude.

Intrinsic motivation theory or the theory of discovery learning belongs to Bruner and it is also known as the Theory of Epistemic Curiosity ${ }^{16}$ i.e. the universal need for knowledge and learning. The stimuli are: newness, variety, complexity or contradiction to the knowledge previously acquired. The pupil basically explores the contents of the manuals and it is important that these contents should stimulate his/her curiosity.

Self-determination theory (Edward Deci, Richard Ryan) ${ }^{17}$

The individual is free to choose a task and commits to achieving it. The individual is therefore genuinely motivated on condition that the social environment allows him/her to satisfy three needs of psychological nature:

- $\quad$ need for autonomy;

- $\quad$ need for competency;

- $\quad$ need for networking ( socialisation).

In this case, the teacher's ability to reward the pupil is extremely important. On the one hand, the pupils' results should be praised; on the other hand, the pupils should be also signalled on their shortcomings which should be corrected so that they should not have the feeling that their skills may never be breached and they may further commit to even more difficult tasks.

Self-determination theory of motivation - the pupils set a specific task for a personal goal or interest. The pupils self-monitor themselves by analysing the achievement of the objectives guiding their learning behaviour, identify the successes and the failures and their causes. The role of the teacher is to collaborate with the pupils on elaborating the plan, to support the latter in choosing the alternatives and to permanently give them confidence.

\footnotetext{
16 Ibidem, page 17

17 Deci, E.L., Vallerand, R,J., Pelletier, L.G., Ryan, R.M. "Motivation and Education: The Self - Determination Perspective" in Educational Psychologist, 26 (3\&4), 1991, page 325
} 
A sensitive issue emerges when the pupil feels that he/she needs the teacher's help and lacks the courage to seek it as he/she associates it with lack of skills. It is the teacher's ability to stay in permanent communication with the pupils, to focalise them on the effort in a customised manner and to facilitate collaboration among pupils in class.

\section{Motivation in school context. Rolland Viau's model ${ }^{18}$}

According to the model, the learning motivation is affected by:

- $\quad$ internal factors (dynamics of the pupil's motivation);

- external factors (pedagogical activity, atmosphere in class, assessment manner and rewarding system, teachers' qualities) - Figure 2.

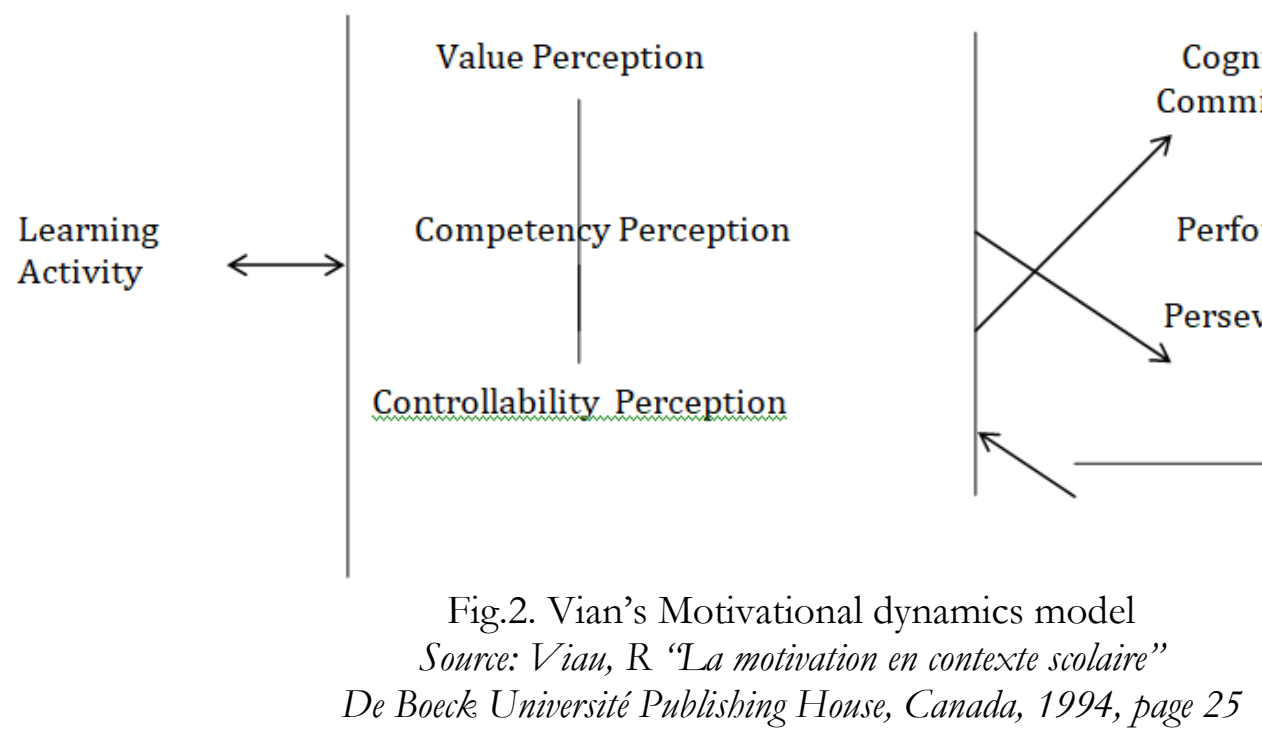

\section{David Ausubel's Theory ${ }^{19}$}

This is a conscious/significant learning theory (meaningful learning) which affirms that in addition to skills, motivation is the second factor influencing the school performance.

The motivation has three types of impulses:

- $\quad$ cognitive (the need to know and solve problems);

- $\quad$ self-assertion ("Ego/Self - enhancement drive") - good marks, being top of the class, appreciation of the teacher;

- $\quad$ affiliation impulse ("affiliative drive") - ensuring affiliation to a group which the pupil considers superior.

The teacher acts intuitively or by his/her ability and therefore creates some situations which generate a "cognitive dissonance" in order to stir one's curiosity.

Starting from this very model of Ausubel, an ample research entitled "Motivation and Learning" was conducted in Romania in $2011^{20}$, on a sample of 30 schools, 12 secondary schools, 567 pupils, 355 teachers (table 1 )

\footnotetext{
18 Viau, $R$ "La motivation en contexte scolaire" Ed. De Boeck Université, Canada, 1994, p.25

${ }^{19}$ Ausubel, D, Robinson, F. "Learning at School - An Introduction to Pedagogical Psychology" Didactică şi Pedagocică Publishing House, Bucharest, 1981, page 27

${ }^{20}$ Cuciureanu, M (coord) "Pupils' Motivation and Learning", I.S.E. Publishing House, Bucharest, 2015, p.28-30
} 
Table 1. Learning motivations for pupils in Romania

\begin{tabular}{|c|c|c|c|}
\hline \multicolumn{4}{|c|}{ Reasons why the pupil learns } \\
\hline & & $\underline{\text { Pupils }}$ & $\underline{\text { Teachers }}$ \\
\hline a) & For a successful career & $\overline{70.6 \%}$ & $19.0 \%$ \\
\hline b) & It will be useful in the future & $43.0 \%$ & $52.0 \%$ \\
\hline c) & Attractive materials & $49.0 \%$ & $40.0 \%$ \\
\hline d) & For good marks & $12.0 \%$ & $37.0 \%$ \\
\hline e) & For the teachers' quality & $47.0 \%$ & $26.0 \%$ \\
\hline f) & For originality of teaching & $53.0 \%$ & $23.0 \%$ \\
\hline g) & At their parents' insistence & $40.0 \%$ & $16.0 \%$ \\
\hline h) & Out of fear of their teachers & $24.0 \%$ & $4.5 \%$ \\
\hline \multicolumn{4}{|c|}{ How they learn } \\
\hline a) & Pupils pay attention to teachers & $44.0 \%$ & $60.0 \%$ \\
\hline $\begin{array}{l}\text { b) } \\
\text { ov }\end{array}$ & $\begin{array}{l}\text { Pupils combine teaching with their } \\
\text { nowledge }\end{array}$ & own knowledge & $42.0 \%$ \\
\hline $\begin{array}{l}\text { c) } \\
\log \end{array}$ & $\begin{array}{l}\text { Pupils memorise information } \\
\text { ly }\end{array}$ & $33.0 \%$ & $46.0 \%$ \\
\hline & $\begin{array}{l}\text { Pupils often ask for their parents' } \\
\text { ith homework }\end{array}$ & $33.0 \%$ & $43.0 \%$ \\
\hline e) & $\begin{array}{l}\text { Pupils seek to transpose knowledge } \\
\text { d in everyday life }\end{array}$ & $30.0 \%$ & $37.0 \%$ \\
\hline f) & $\begin{array}{l}\text { Pupils learn mechanically, by heart } \\
\text { at enhances pupils' motivation }\end{array}$ & $28.0 \%$ & $39.0 \%$ \\
\hline a) & Attractive classes & $35.0 \%$ & $80.0 \%$ \\
\hline b) & Applicative lessons & $54.0 \%$ & $61.0 \%$ \\
\hline c) & Atmosphere in classroom & $53.0 \%$ & $60.0 \%$ \\
\hline
\end{tabular}
Source: Cuciureanu, $M$ (coord) works quoted, p. 30

In addition, the study emphasized the causes invoked by pupils to justify their lack of learning motivation: they lack appropriate conditions, personal limits, lack of time, lack of interest, fear to be labelled as "nerds", family shows no interest, lack of appreciation from teachers, conviction that learning is completely useless.

\section{Relation between motivation and job satisfaction}

"Work means a series of mental and operational conscious human manifestations by which the man acts on the environment, on himself and the others in order to satisfy his needs, interests, aspirations, to attract various goals etc... The profession defines the volume of general and expert knowledge, abilities and attitudes that a person needs in order to carry out a type of activity generated by the specific division of work. It is in relation to one's profession that the expert and some general knowledge are acquired. The same applies to abilities and attitudes which confer content to a profession. The profession is generated by minute division of work and defines the activity carried out by the workforce in concrete conditions at their workplaces" 21 Motivation and satisfaction are correlated to the individual performance which may be positively or negatively influenced by certain characteristics of the profession at workplace ${ }^{22}$.

\footnotetext{
21 Omer, I. "Work Psychology - Syntheses" Spiru Haret University - Faculty of Sociology, Bucharest, 2009, available at http://.spiruharet.ro/facultati/sociologie-psihologie/biblioteca/42858fc4f9705fbad6291433746ce8b2.pdf

22 Bajenaru, L., Tomescu, M - "Impact of Work Satisfaction on the Research Activity. Case Studies" in the Romanian Magazine for Computer Science and Automatics, vol.28, No.4, 51-66, Bucharest, 2018
} 


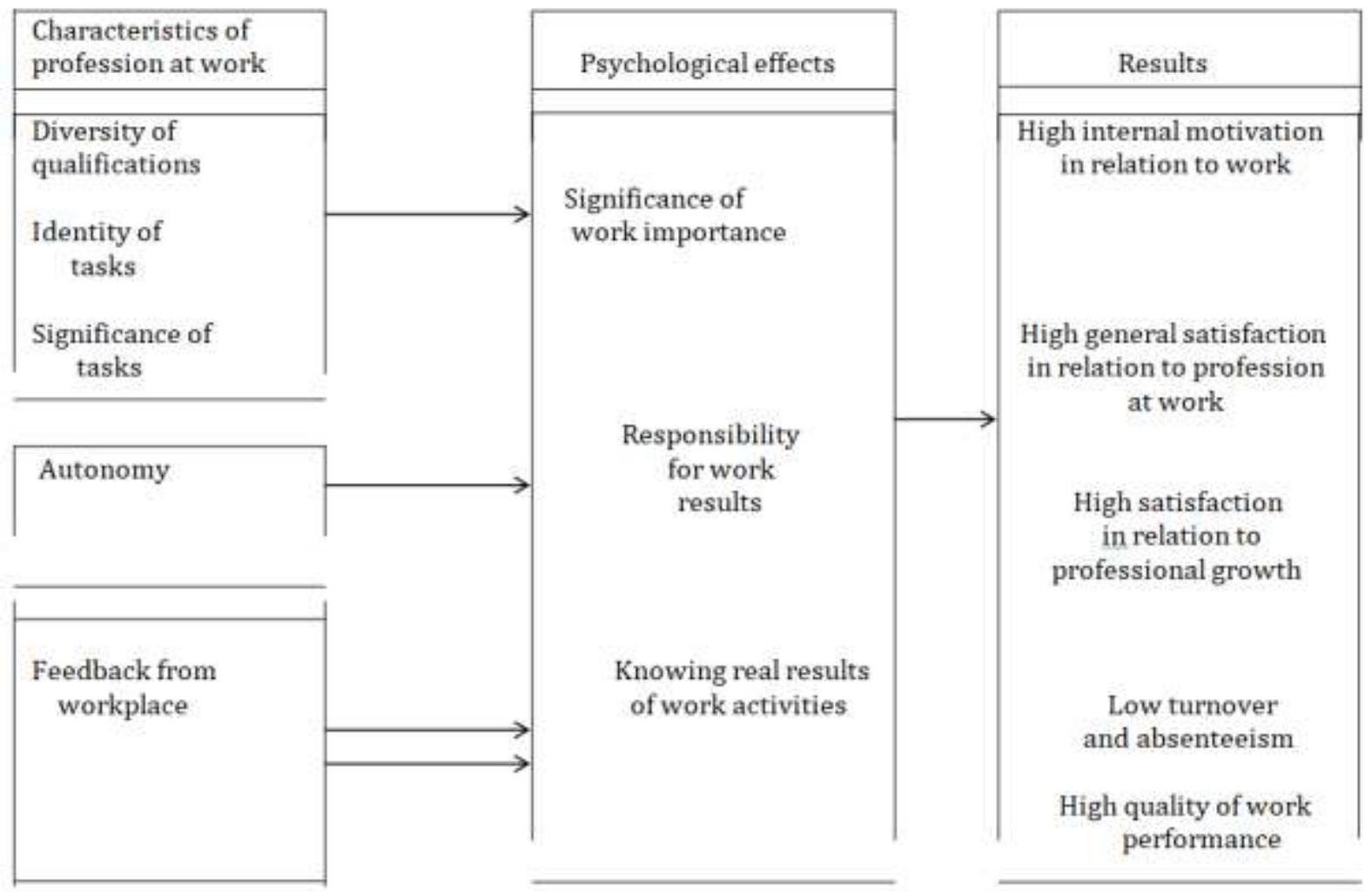

Fig.3. Relation between characteristics of profession at work and performances of employees' work

Source: Băjenaru, L, Tomescu, $M$ - quoted works, page 53

Job satisfaction is a positive emotional condition which emerges under the influence of a person's perception on the aspects of his/her work - nature and difficulty of tasks, salary correlated to the effort made, working conditions, colleagues, managers' attitude, people's behaviour before the organisation with which they have professional relationships, culture of the organisation to which they belong, all these combined with the individual characteristics of a person.

The most popular theories on job satisfaction are ${ }^{23}$ :

Table 2. Job satisfaction theories

\begin{tabular}{|l|l|}
\hline Name of theory & Content \\
\hline \multirow{5}{*}{ Two-factor theory } & $\begin{array}{l}\text { Elaborated by F. Herzberg (1959) pinpoints two categories of } \\
\text { factors: } \\
-\quad \text { satisfaction-related factors: personal achievements, } \\
\text { recognition, promotion opportunities, personal growth } \\
\text { through work: } \\
- \text { dissatisfaction-related factors: work supervision, work } \\
\text { conditions, interpersonal relations, salary, job security, } \\
\text { administration and policy of the institution. }\end{array}$ \\
\hline Equity theory & $\begin{array}{l}\text { Elaborated by John S. Adams states that people compare their } \\
\text { effort to the compensation they obtain in return and make } \\
\text { decisions to change either their job or the organisation. They } \\
\text { also react when they see inequities between the rewards they }\end{array}$ \\
\hline
\end{tabular}

${ }_{23}$ Zlate, S., Cucui, G. "Motivation and Performance in Higher Education" The $6^{\text {th }}$ International Conference Edu World

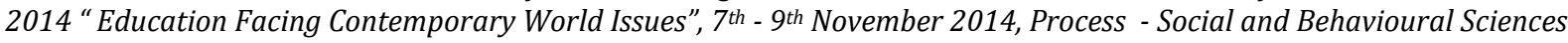
“, 180, 2015, pages 468-476 


\begin{tabular}{|l|l|}
\hline Discrepancy theory & are granted and the ones granted to their colleagues. \\
\hline Fairness theory & $\begin{array}{l}\text { Elaborated by G. Johns states that "job satisfaction originates } \\
\text { in the discrepancy between forecasted results and actual results } \\
\text { at work". }\end{array}$ \\
\hline $\begin{array}{l}\text { According to this theory, there are two types of fairness: } \\
\text { - distributive fairness - when people consider that the reward } \\
\text { is fair and in line with their work; } \\
\text { - procedural fairness - when people consider that the manner } \\
\text { used in assessing their work is accurate. }\end{array}$ \\
\hline
\end{tabular}

Source: Adapted according to Zlate, S., Cucui, G. quoted works, pages 468-476

In order to assess job satisfaction, the organisational psychology uses two models:

- JDI ( Job Descriptive Index) composed of simple sentences to which people respond YES or NO with regard to satisfaction: work content, interpersonal relations, facilities, organisational framework, material conditions;

- MSQ (Minnesota Satisfaction Questionnaire) uses the 5 to 7 point Lickert scale from "highly satisfied" to "extremely dissatisfied" and calculates a total score for all the elements constituting satisfaction.

\section{Intercultural perspective - integral part of the didactic approach}

The intercultural education seeks to form skills required to live alongside the others by getting to know them, their history, traditions and spirituality. This approach is difficult as each individual is the product of his/her culture. Additionally, the intercultural education equally focuses on both minority and majority members so as to foster a constant dialogue on an equal footing.

The intercultural education mainly focuses on diversity. In the whole curriculum and the whole pedagogical process the pupils should be presented the reality from different angles so that they should get familiar to different approaches, accept points of view different from theirs, communicate and cooperate in culturally heterogeneous groups.

Another dimension of the interculturalism is equity. The pupils have to understand and not to memorise the concepts of intolerance, discrimination, racism. They have to be models of behaviour in class, in school, in activities carries out in cooperation with other schools and institutional institutions from the country and abroad, in the family. They will understand and accept equity of access for everybody to educational resources, assessment of all people using the same measurement unit, similar rewards of performances and skills used for everybody.

The current legislation and projects in the educational field, as well as the public policies elaborated by the Ministry of National Education, confirm the political will to take into consideration all national minorities as equal dialogue partners and to encourage the international projects which aim to integrate Romania's interculturalism policy into the European education.

At school level there is still room for improvement as the teachers with interculturalism option are neither the ones to come close to retirement age nor the one to have reached the retirement age. For the future euro-specialists which the school have to form, it is required to use constructivist pedagogy where, in addition to the cognitive dimension, the teacher is able to encourage different opinions, to be the cultural mediator, to moderate dialogues. The teacher provides only some of the information and encourages the pupils to search, expose, explain the information that they find themselves, using different sources. Within the framework of constructivist pedagogy, we seek to lay emphasis on the role of the pupil. We have to be fully responsible in accepting the concept of teacher-pupil partnership in which the latter should be encouraged to express his/her points of view even though they may seem divergent from his/her teacher's opinions. The pupils have to feel that their teachers and colleagues value them for everything that makes them special in terms of cultural, ethnic and religious identity. Once they feel discriminated, they will develop inferiority complexes which they hide, interiorise, and become uncooperative, indifferent and even aggressive. The education acquired by pupils within 
their family also comes to intervene in the interculturalism equation. The worst situation is when the parents' beliefs and attitudes conveyed to pupils come in contradiction with the values of the efficient intercultural education fostered in schools. This is where the fight is fought but the resource to improve education is also present. It is the "utopia" as defined by Jacques Delors in the International Commission Report on the education of the $21^{\text {st }}$ century: "a vital utopia to leave the dangerous circle fed by cynicism and resignation" 24 .

The quality of knowledge in the globalised society means to understand the foreigner and the foreign context when we refer to a cultural environment different from our own. The constructivist and postmodernist conception states that intercultural learning is based on education and relates to its social context. This means dialogue, social interaction, actively listening to the others.

Romania's action directive is a better integration of the objectives relating to culture and education - education by and for culture. ${ }^{25}$ "Support will mainly be given to courses which seek assimilation of elements relating to art history and culture, education for cultural patrimony ... by using an integrating vision which should facilitate insertion of the cultural-artistic education in teaching some disciplines under other curricular areas (in accordance with examples of good practices existing both nationwide and worldwide). Teachers will be provided lifelong training courses on intercultural education. These courses will foster principles of non-discrimination and equal chances... In addition, one will seek to develop professional skills of staff working within public culture institutions in the field of intercultural education... One will develop teachers' skills to use pedagogical approaches which count on culture as strategic resources to help pupils grow and as educational instrument, which exploits arts and cultural patrimony as teaching resources".

An intercultural education may not be conceived without communicative skills in foreign languages. At present, it is required to have a new didactic approach in teaching/learning modern languages, an approach in which the teacher has to integrate the cultural elements, irrespective of the thematic content approached. "The language represents not only a mere communication instrument, which allows factual conveyance of information, but also a cultural treasure reflecting the history and the evolution of a people, gathered throughout their existence, behaviours, attitudes, values and mentalities, an entire existential philosophy. Therefore, the history of a people, the social norms and bases of a society, are essential factors in understanding the culture and the civilisation of that people and consequently, it is important for those who learn the language of that people to be able to understand and accurately interpret the attitudes and behaviours staged by their interlocutors in their communication acts, whether it is about gestures or historical/cultural references."26

Interculturalism also involves plurilingual competences, whereas elaboration of curriculum and formation of teachers involve major changes and substantial costs. Additionally, the plurilingual education should be promoted both within schools and in society, through mass media and cultural events.

The European Council has elaborated the guidance document "Common European Framework of References for Languages: Learning, Teaching, Assessment" with the central objective to form the intercultural communication skill according to which the central objective of the initial training of foreign language teachers is communication with an integrating content composed of three dimensions:

- $\quad$ cognitive dimension - knowing the target language and culture;

- $\quad$ emotional dimension - behaviour in relation to target culture;

\footnotetext{
${ }^{24}$ Lazăr, E., Stăvărache, E. "Creativity in Teaching and Training for a Better School Behaviour" County Symposium, $1^{\text {st }}$ edition, $1^{\text {st }}$ volume, Roșiori de Vede, 2017, page 74

25 Ministry of Culture "Strategy for Culture and National Patrimony 2016-2022" available at

file:///c:Users/Acasa/Downloads/SCPN\%202016-2022inavizareculturala\%20\%20romana.pdf, pages 62-64

${ }_{26}$ Mitroi, A.M. "Intercultural Perspective - Integral Part of the Didactic Approach" in ITEACH Magazine: didactic

experiences, February $7^{\text {th }} 2013$
} 
- pragmatic dimension - communication skill.

The objective of the Bologna process is to form some personalities socially capable to integrate themselves in the national and international economic system. At present, diversification of the educational offer and formation of plurilingual specialists represent an imperative both at preuniversity and university level.

\section{Quality of the educational service - resultant of pupils' and teachers' satisfaction}

The clients of educational services are both pupils and their families, on the one hand, and society as a whole, on the other hand. "The education of my child contributes to his/her wellbeing, by fostering a stable and democratic society". ${ }^{27}$

The quality of the pupils' training and education process is proven by their learning results, on the basis of the curriculum development strategies, teaching and learning methods, assessment, examination and certification.

The European or global concerns are in line with the development of the cross-national education, without borders (borderless or cross-border education). UNESCO and OECD have elaborated and adopted orientations (guidelines) concerning the quality of the services provided by the educational institutions with focus on the need to operate with performance ratios which include interculturalism elements.

Providing pupils with a performing training, as accepted by standards and practices of the European education establishments, confers schools an international dynamics and Romanian society more confidence that their explicit and implicit expectations on performance of the Romanian pre-university education establishments will be satisfied. As the demand for educational services is at present of an unprecedented dynamics in terms of both complexity and rhythm of change, the pre-university education establishments should have a clear vision on the future and anticipate changes which may emerge either on the education market or the labour market, permanently keeping in touch with the upstream and downstream partners. These processes unequivocally highlight the importance of teachers' permanent education so that they may adapt to the needs of their pupils and the society. Lifelong/permanent education is an integrating concept which encompasses all dimensions of the educational act both in temporal terms (lifelong education) and in spatial terms, articulating all influences and actions exercised on the trainables in a formal structure (school) or a non-formal and informal structure (life- wide education). Educational orientation has considerably evolved under the influence of the fundamental changes occurred, from mere acquisition of knowledge ( "to know") and formation of skills ("to learn to do") to development of attitudes ("to want to be") and of personality as a whole ("to learn to be") and social and professional skills ("to learn to be with others"). All these domains contribute to intensify development and help the individual to become within society ("to learn to become").

The quality is essentially assessed by the pupils and their parents after educational services are provided. They opt for a school or a programme prior to understanding how useful they are. There is definitely preliminary information on a certain education establishment, yet its actual value is appreciated at the end of the schooling period, depending on the performances of which graduates of such school are capable. Romania's accession to the European Union led to enhanced importance attached to scientific and technical disciplines. Review was made of the contents. Stronger connections with life have been created so that science and research should be integrated in the European space. New educations emerged: civics, moral and religious education, aesthetic education, education for peace and cooperation.

The collaboration among teachers of different specialties, the partnership between school and local community, pursue an education based on knowledge and truth which should increase the confidence of the society members in the educational force of the school.

${ }^{27}$ Friedman, M. "Free to Choose a Personal Point of View " All Publishing House, Bucharest, 1998, page 274 
Pupils and teachers satisfied with their work mean quality of the education capable to prepare the graduate as an individual with equal rights in an economically, politically, culturally and religiously fragmented world.

\section{Conclusions}

The educational process should ensure knowledge in a professional field and include elements of one's own cultural system as well as elements of other socio-cultural systems so that future specialists may work together in national or cross-border multicultural teams.

The motivation for learning, built and maintained in a professional manner among pupils, constitutes premises for a successful educational act. Keeping pupils' motivation at high levels stimulate, in its turn, the motivation among teachers for a creative, attractive and efficient performance, as this is the main source of job satisfaction in their case.

The postmodern society in which we all evolve at present imposes interculturalism as an integral part of the didactic approach, giving priority to constructivist pedagogy based on understanding and accepting diversity and equity. The educational act becomes a teacher-pupil partnership in which free thinking is accepted and stimulated, as well as the exchange of ideas which contribute to formation of personality and accountability of the pupils who are therefore prepared to become good specialists and also active citizens within their community.

Ensuring quality education means aligning to reference standards, and in particular to the level to which the beneficiaries' expectations are satisfied. The quality of the education is assessed and controlled through activities specifically regulated by internal and external bodies (ARACIP Romanian Agency for Quality Assurance in Pre-university Education) and autonomous and internal agencies.

\section{References}

1. Ausubel, D, Robinson, F. "Learning at School - An Introduction to Pedagogical Psychology" Didactică și Pedagocică Publishing House, Bucharest

2. Bajenaru, L., Tomescu, M - "Impact of Work Satisfaction on the Research Activity. Case Studies" in the Romanian Magazine for Computer Science and Automatics, vol.28, No.4, 51-66, Bucharest

3. Cuciureanu, M (coord) 'Pupils' Motivation and Learning", I.S.E. Publishing House, Bucharest

4. Cuciureanu, M (coord.) - 'Pupils' Culture and Learning", I.S.E. Publishing House, Bucharest

5. Deci, E.L., Vallerand, R, J., Pelletier, L.G., Ryan, R.M. "Motivation and Education: The Self Determination Perspective" in Educational Psychologist, 26 (3\&4)

6. Friedman, M. "Free to Choose a Personal Point of View" All Publishing House, Bucharest

7. Lazăr, E., Stăvărache, E. (2017) "Creativity in Teaching and Training for a Better School Behaviour" County Symposium, $1^{\text {st }}$ edition, $1^{\text {st }}$ volume, Rosiori de Vede

8. Ministry of Culture "Strategy for Culture and National Patrimony 2016-2022" available at http:// wnw.cultura.ro/sites/default/files/inline-files/_SCPN\%202016-2022inavizare.pdf

9. Mitroi, A.M. "Intercultural Perspective - Integral Part of the Didactic Approach" in ITEACH Magazine: didactic experiences, February $7^{\text {th }} 2013$

10. Omer, I. "Work Psychology - Syntheses" Spiru Haret University - Faculty of Sociology, Bucharest, 2009, available at http://.spirubaret.ro/facultati/sociologie-

psibologie / biblioteca/42858fc4f9705fbad6291433746ce8b2.pdf

11. Popenici, St (coord.) -'Learning Motivation and Social Success", I.S.E. Publishing House, Bucharest

12. Viau, $R$ "La motivation en contexte scolaire" Ed. De Boeck Université, Canada

13. Zlate, S., Cucui, G. "Motivation and Performance in Higher Education" The $6^{\text {th }}$ International Conference Edu World 2014 "Education Facing Contemporary World Issues", $7^{\text {th }}-9^{\text {th }}$ November 2014, Process - Social and Behavioural Sciences ", 180 